\title{
ESTUDOS HISTOMORFOMÉTRICO E HISTOLÓGICO DAS LESÕES ÓSSEAS CAUSADAS POR FLÚOR EM AVES ${ }^{1}$
}

\author{
Margarida Buss Raffi ${ }^{2}$, Maria del Carmen Méndez ${ }^{3}$ e Franklin Riet-Correa ${ }^{3}$
}

\begin{abstract}
Raffi M.B., Méndez M.C. \& Riet-Correa F. 1997. [Histomorphometric and histological evaluations of the bone lesions caused by fluoride in chickens.] Estudo histomorfométrico e histológico das lesões ósseas causadas pelo flúor em aves. Pesquisa Veterinária Brasileira 17(2):69-76. Depto Clínica Médica Veterinária, Setor de Anatomia Patológica, Faculdade de Agronomia e Medicina Veterinária, UFMT, Av. Fernando Correa da Costa s/n $\mathbf{n}^{\circ}$, Cuiabá, MT 78060-900, Brazil.

Sodium fluoride was administered in the water to 2 groups of 25 Shaver female poultry. Group A received fluoride from 1 to 120 days of age and group B from 61 to 120 days. Each group was divided into 5 treatments, with 5 chickens each, which received $0,25,50,200$, and $400 \mathrm{ppm}$ of fluoride in the water, respectively. All animals were killed at 120 days of age. For histomorphometric studies the left femur and tibia were used, and for histologic studies the right femur and tibia. In the cortical bone, cortical porosity was slightly increased by fluoride, but the differences with the control group were not significant. Cortical thickness increased in the animals treated with fluoride $\left(p<0,05, r^{2}=0,59\right)$. In the trabecular bone, of group $A$, trabecular thickness (TT) $\left(p<0,05, r^{2}=0,63\right)$ and trabecular bone volume (TBV) $\left(p<0,05, r^{2}=\right.$ 0,72 ) increased in treatments receiving $25-200 \mathrm{ppm}$, and decreased in the $400 \mathrm{ppm}$ treatment, as it was demonstrated by quadratic regression analysis. In group B there was a positive linear correlation on TT $\left(p<0,05, r^{2}=0,98\right)$ and TBV $\left(p<0,05, r^{2}=0,77\right)$ with fluoride ingestion.The osteoid surface was also positively correlated with the amount of fluoride ingested by the animals $\left(p<0,001, r^{2}=0,80\right)$. These results suggest that fluoride improves osteoblastic function resulting in increased osteoid production and bone apposition. In the other hand, in the animals treated with $400 \mathrm{ppm}$ of fluoride for 120 days bone apposition was reduced suggesting a functional alteration of the osteoblasts or improved bone resorption. In the histological study of bone tissue all animals that received fluoride showed an increased trabecular thickness which was more marked in the 200-400 ppm treatments. In chickens treated with 200-400 ppm of fluoride osteoblasts and osteoclasts were more numerous suggesting an increased bone turnover. In cortical bone Haversian canals were narrowed on the periosteal surfaces and resorption spaces were enlarged on the endosteal surfaces.
\end{abstract}

INDEX TERMS: Fluoride, bone, bone histomorphometry, poultry, fluorosis.

\footnotetext{
${ }^{1}$ Aceito para publicação em 23 de abril de 1997.

Trabalho financiado pelo CNPq. Parte da Tese de Mestrado do primeiro autor, realizada na Faculdade de Veterinária, Universidade Federal de Pelotas (UFPel), Rio Grande do Sul (RS).

2 Depto de Clínica Médica Veterinária, Setor de Anatomia Patológica, Faculdade de Agronomia e Medicina Veterinária, Universidade Federal de Mato Grosso (UFMT), Av. Fernando Correa da Costa s/nº, Cuiabá, Mato Grosso (MT) 78060-900.

${ }^{3}$ Laboratório Regional de Diagnóstico, Faculdade de Veterinária/UFPel, Pelotas, RS. 96010-900. Bolsista CNPq.
}

SINOPSE.- Fluoreto de sódio foi administrado na água de 2 grupos de 25 aves, fêmeas, da raça Shaver. 0 grupo A recebeu flúor do $1^{\circ}$ ao $120^{\circ}$ dia de idade e o grupo $\mathrm{B}$ do $61^{\circ}$ ao $120^{\circ}$ dia de idade. Cada grupo foi dividido em 5 níveis de tratamento: 0, 25, 50, 200 e 400 ppm de flúor, com 5 animais por tratamento. Todos os animais foram sacrificados aos 120 dias de idade. Para o estudo histomorfométrico foram coletados o fêmur e a tíbia esquerdos, e para o estudo histológico foram coletados fêmur e tíbia direitos. No estudo histomorfométrico do osso compacto observou-se um 
discreto aumento da porosidade cortical, que não foi estatisticamente significativo. A espessura do osso cortical aumentou nos animais tratados com flúor $\left(\mathrm{p}<0,05, \mathrm{r}^{2}=0,59\right)$. No osso trabecular, do grupo A, houve um aumento da espessura trabecular $(\mathrm{ET})\left(\mathrm{p}<0,05, \mathrm{r}^{2}=0,63\right)$ e do volume trabecular ósseo (VTO) (p<0,05, $\left.\mathrm{r}^{2}=0,72\right)$ até a dose de $200 \mathrm{ppm}$; e, na dose de $400 \mathrm{ppm}$, ocorreu um decréscimo, demonstrado pela regressão quadrática obtida na análise de regressão. No grupo B houve um aumento progressivo da ET $\left(\mathrm{p}<0,05, \mathrm{r}^{2}=\right.$ $0,98)$ e do VTO $\left(p<0,05, r^{2}=0,77\right)$ diretamente relacionado com a dose de flúor. A superfície de osteóide (SO) apresentou, também, um aumento gradativo relacionado com a dose, nos animais tratados com flúor $\left(\mathrm{p}<0,001, \mathrm{r}^{2}=0,80\right)$. Esses resultados sugerem que o flúor estimula a função osteoblástica, resultando em aumento da SO, e consequentemente maior aposição óssea. No entanto, nos animais tratados com 400 ppm, durante 120 dias, esse estímulo sobre a aposição óssea não foi tão evidente, sugerindo que o flúor determina alguma alteração funcional sobre os osteoblastos ou um aumento da reabsorção óssea. Histologicamente, observou-se espessamento trabecular nos animais tratados com flúor, mais marcado nas doses de 200 e $400 \mathrm{ppm}$, em ambos os grupos. Sobre a superfície trabecular, dos animais tratados com 200 e 400 ppm, evidenciou-se, principalmente, osteoblastos ativos e osteoclastos, sugerindo um aumento da remodelação óssea. No osso cortical observouse diminuição dos canais de Havers, próximos a superfície periosteal, e aumento das lacunas de reabsorção próximas a superfície endosteal.

TERMOS DE INDEXAÇÃO: Flúor, ossos, histomorfometria óssea, aves, fluorose.

\section{INTRODUÇÃO}

A intoxicação crônica por flúor, denominada comumente de fluorose, é a forma mais frequente de intoxicação observada nos animais domésticos, e ocorre pela ingestão de pequenas doses de flúor, por um longo período de tempo (Shupe \& Olson 1983).

A contaminação dos animais pode ocorrer por diversas fontes: a) vegetações que crescem em solos com alto conteúdo de flúor; b) água com alto conteúdo de flúor; c) suplementos minerais que não tenham sido apropriadamente desfluorizados; e d) pastagens contaminadas pela emissão de flúor de diversos tipos de indústria (Shupe 1967, Suttie 1980, Ammerman 1980).

Na região sul do Rio Grande do Sul já foram realizados dois trabalhos sobre contaminação do meio ambiente por flúor: no município de Rio Grande, onde a poluição ambiental foi causada pelo processamento de rocha fosfática para a produção de adubo (Riet-Correa et al. 1983) e no município de Bagé, no qual a poluição ambiental foi produzida pela combustão de carvão mineral por uma usina termoelétrica (Riet-Correa et al. 1986).

Os sinais clínicos mais evidentes na fluorose ocorrem nos ossos e dentes devido a grande afinidade do flúor por tecidos mineralizados (Eanes 1983). Shupe \& Olson (1983) rela- tam que animais expostos ao flúor podem apresentar, uma ou mais, das seguintes alterações ósseas: osteoporose, osteoesclerose, hiperostose, osteofitose e osteomalácia. Alguns autores associam o quadro de osteosclerose à ingestão de pequenas doses de flúor por um longo período de tempo, enquanto que osteoporose e osteomalácia são relacionadas à ingestão de altos níveis de flúor (Coutelier et al. 1978, Daijei 1984, Krishnamachari 1986). Outras alterações ósseas associadas à intoxicação por flúor são atrofia e necrose de osteoblastos e osteócitos (Krook \& Maylin 1979, Mores \& Bellaver 1984). Os osteons podem apresentar tamanho e forma irregulares com distribuição anormal dos osteócitos, bem como canais de Havers de diversos diâmetros (Shupe et al. 1963, Shupe \& Olson 1983, Riet-Correa et al. 1983, Chongwan et al. 1983).

Os ossos podem ser estudados, também, pela técnica de histomorfometria, usualmente realizada em ossos não descalcificados, inclú́dos em solução de metil metacrilato ou resina de poliéster, que permite a realização de cortes através de micrótomo de impacto ou pelo desgaste manual. Esta técnica tem sido utilizada para estudo de ossos com fluorose, pois possibilita visualizar o osso calcificado e o não calcificado (osteóide), sendo possível, também, quantificar estruturas do tecido ósseo como: espessura trabecular, volume trabecular ósseo, superfície de osteóide, número de osteócitos, superfície lacunar periosteocítica, porosidade cortical, diminuindo, assim, a subjetividade dos achados histológicos (Bang et al. 1978, Baud et al. 1978, Boivin 1978, Boivin \& Baud 1978, Baron et al. 1983, Boivin et al. 1987, Chavassieux et al. 1987).

O objetivo deste trabalho foi estudar as lesões ósseas causadas pelo flúor em aves, quando administrado em diferentes doses e por dois diferentes períodos de duração, 60 e 120 dias.

\section{MATERIAL E MÉTODOS}

Neste estudo foram utilizadas 50 aves, fêmeas, da raça Shaver, com 1 dia de idade, as quais foram alimentadas com ração balanceada, com as necessidades alimentares adequadas a cada fase do desenvolvimento. $\mathrm{O}$ flúor foi ministrado sob a forma de fluoreto de sódio, dissolvido na água de bebida dos animais.

Os animais foram divididos, completamente ao acaso, em 2 grupos, quanto ao período de suplementação com flúor. Estes grupos foram sub-divididos em 5 níveis de tratamento com flúor (5 animais por tratamento).

Grupo A: recebeu suplementação com flúor do $1^{\circ}$ ao $120^{\circ}$ dia de idade, com níveis de tratamento de $0,25,50,200,400$ ppm.

Grupo B: recebeu suplementação com flúor do $61^{\circ}$ ao $120^{\circ}$ dia de idade, com níveis de tratamento de 0, 25, 50, 200 e 400 ppm.

No final de cada período de suplementação os animais de cada grupo foram sacrificados, sendo coletados, os dois fêmures e as duas tíbias.

Para o estudo histomorfométrico o fêmur e a tíbia esquerdos, de cada animal, foram fixados em etanol e incluídos em resina de poliéster, desgastados manualmente até aproximadamente $100 \mathrm{~mm}$ ou cortados em micrótomo ${ }^{4}$ de impacto, de 5 a $10 \mathrm{~mm}$ de espessura e corados pela fucsina básica.

\footnotetext{
${ }^{4}$ Reichert-Jung 2040, navalha de tungsteno.
} 
Para o estudo do osso compacto foram utilizados cortes transversais da diáfise da tíbia de cada animal, na qual foram avaliadas a espessura e a porosidade do osso cortical. Para determinar a espessura, o osso cortical foi medido desde a superfície periosteal até a superfície endosteal, com auxílio de uma régua acoplada a ocular com aumento de $10 x$ e objetiva de $4 x$. $O$ valor final para cada animal foi determinado através da média dos valores obtidos, expressa em micrômetros. A porosidade foi determinada com auxílio de uma lente de sobreposição com 100 pontos representados por + , acoplada à ocular 10x, e utilizando objetiva 20x. Foram contados os pontos que incidiram sobre as cavidades, estabelecendo-se o valor final em percentual, de acordo com a seguinte fórmula:

Porosidade $=\underline{\mathrm{n}^{\mathrm{o}} \text { de pontos em cavidades } \times 100}$ $\mathrm{n}^{\mathrm{o}}$ total de pontos

Para o estudo do osso trabecular utilizaram-se cortes longitudinais da epífise de fêmur, avaliando-se a espessura trabecular (ET), o volume trabecular ósseo (VTO) e a superfície de osteóide (SO). A ET foi determinada realizando-se medidas da largura das trabéculas ósseas, utilizando-se a mesma lente usada para medir o osso cortical da diáfise, com ocular de 10x e objetiva de 4x. O VTO foi realizado com a mesma lente utilizada para determinar a porosidade do osso cortical. Os valores foram obtidos pela contagem de pontos que incidiram sobre o osso trabecular em relação aos pontos que incidiram na medula ou cartilagem, utilizando-se ocular e objetiva de 10x. O valor final para cada animal foi expresso em percentual com a seguinte fórmula:

VTO $=\underline{\mathrm{n}^{\mathrm{o}} \text { de pontos sobre osso trabecular } \mathrm{x} 100}$ $\mathrm{n}^{\mathrm{o}}$ total de pontos

Para determinar a SO, utilizou-se uma lente de sobreposição traçada com linhas e pontos de intersecção acoplada a ocular com aumento de 10x e objetiva de 10x. Foram contados os pontos de interseç̧ão que incidiram sobre a superfície de osteóide, expressando o valor final em percentual de acordo com a seguinte fórmula:

$$
\text { SO }=\frac{\mathrm{n}^{\mathrm{o}} \text { de intersecções que incidiram sobre osteóide } \mathrm{x} 100}{\mathrm{n}^{\mathrm{o}} \text { total de intersecções }}
$$

Os dados histomorfométricos foram analisados segundo o delineamento experimental inteiramente ao acaso, cujos tratamentos constituíram um esquema fatorial $2 \times 4$ ( 2 períodos de tempo e 4 concentrações de flúor) onde foi efetuada a análise da variância. Os períodos foram comparados através do teste de d.m.s. de Fisher e, para concentrações foi realizada a análise de regressão polinomial utilizando-se o SANEST - Sistema de Análise Estatística para microcomputador (Zonta \& Machado 1982).

Para o estudo histológico o fêmur e a tíbia direitos, de cada animal, foram fixados em formol, descalcificados a vácuo em ácido fórmico e citrato de sódio (Luna 1968), incluídos em parafina, cortados a $6 \mathrm{~mm}$ e corados pela técnica de hematoxilina-eosina. Foram examinados cortes transversais de diáfise de tíbia e cortes longitudinais da epífise de fêmur.

A quantidade de flúor presente na cinza óssea foi determinada através de um medidor de íons específico, segundo a técnica de McCann (1968), utilizando-se uma amostra da tíbia direita, de um animal por grupo.

\section{RESULTADOS}

Histomorfometria

Os resultados obtidos no estudo da porosidade do osso cortical são apresentados no Quadro 1, e os da espessura do

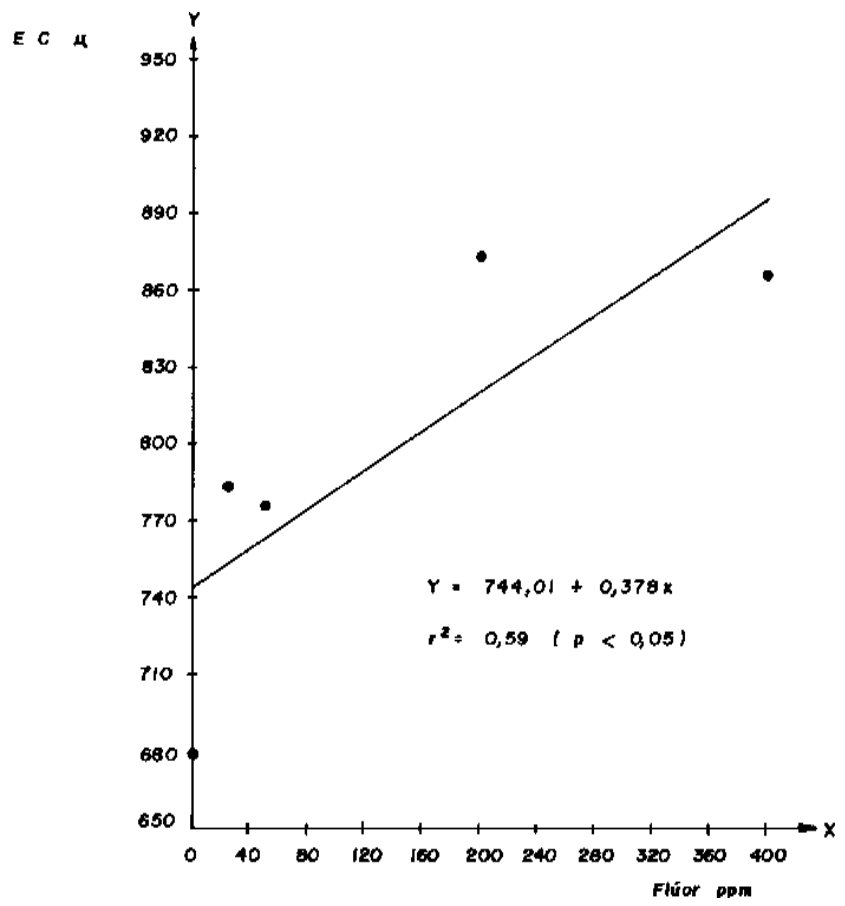

Fig. 1. Representação gráfica da regressão linear da espessura do osso cortical (EC), dos animais tratados com diferentes níveis de flúor.

Quadro 1. Porcentagens de porosidade do osso cortical da diáfise da tíbia, dos frangos do grupo A e B, nos diferentes níveis de tratamento

\begin{tabular}{ccc}
\hline \multirow{2}{*}{$\begin{array}{c}\text { Níveis de flúor } \\
\text { ppm }\end{array}$} & \multicolumn{2}{c}{ Porosidade \% } \\
\cline { 2 - 3 } & $\mathrm{A}$ & $\mathrm{B}$ \\
\hline 0 & $9,05 \mathrm{~A}^{\mathrm{a}}$ & $9,05 \mathrm{~A}$ \\
50 & $9,58 \mathrm{~A}$ & $10,31 \mathrm{~A}$ \\
200 & $6,46 \mathrm{~A}$ & $11,05 \mathrm{~A}$ \\
400 & $7,69 \mathrm{~A}$ & $14,69 \mathrm{~A}$ \\
& $9,44 \mathrm{~A}$ & $9,78 \mathrm{~A}$
\end{tabular}

a Médias dos tratamentos com mesma letra nas colunas e linhas não diferiram significativamente $(\mathrm{P}>0,05)$ entre si.

osso cortical (EC), na Figura 1, e correspondem à média obtida dos animais dos dois grupos de tratamento A e B (tratados durante 120 dias e 60 dias, respectivamente) nas diferentes concentrações de flúor.

Os valores obtidos no estudo da espessura do osso trabecular (ET), dos animais do grupo A e B nos diferentes níveis de flúor, são apresentados na Figura 2. Na Figura 3 são expostos os valores obtidos para o volume trabecular ósseo (VTO), para animais do grupo A e B alimentados com diferentes concentrações de flúor, e os resultados obtidos da superfície de osteóide (SO) são apresentados na Figura 4, e correspondem à média obtida dos animais dos grupos A e B.

Histologia

No osso trabecular do grupo A observou-se um aumento na espessura trabecular em todos os tratamentos, sendo mais 


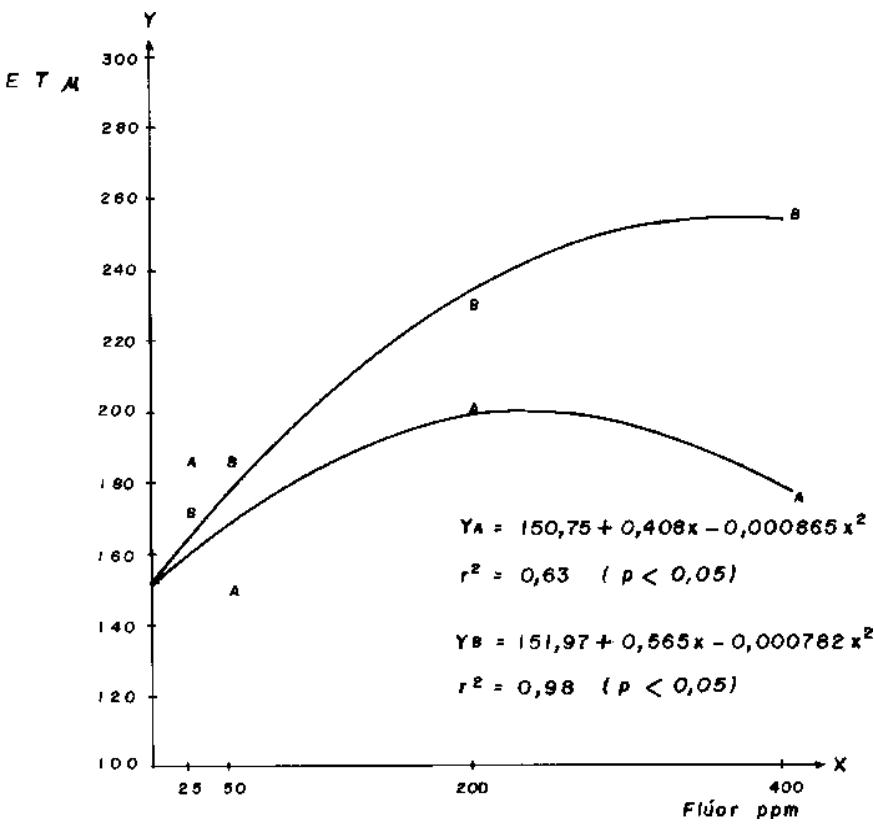

Fig. 2. Representação gráfica da análise de regressão quadrática da espessura trabecular (ET), dos animais dos grupos A e B (tratados durante 120 dias e 60 dias, respectivamente), suplementados com diferentes níveis de flúor.

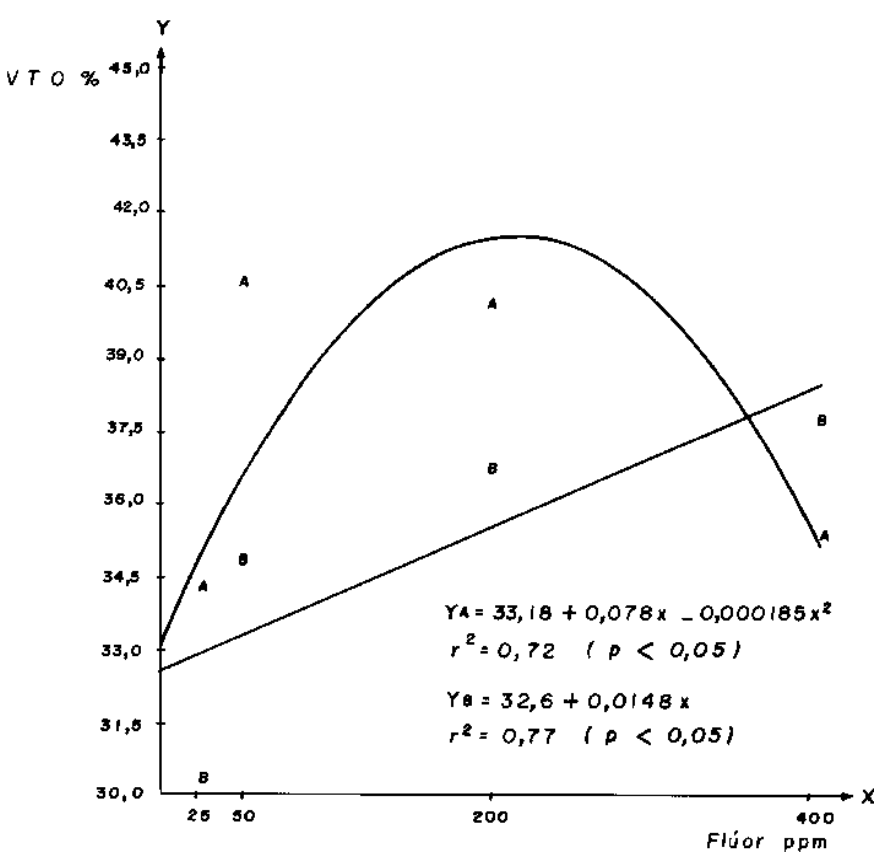

Fig. 3. Representação gráfica da análise de regressão, do volume trabecular ósseo (VTO) dos animais dos grupos A e B (tratados durante 120 dias e 60 dias respectivamente), suplementados com diferentes níveis de flúor.

evidente nos tratamentos de 200 e 400 ppm de flúor e discreta nos restantes.

Nas superfícies trabeculares havia um aumento no número de osteoblastos ativos e, também, de osteoclastos, nos

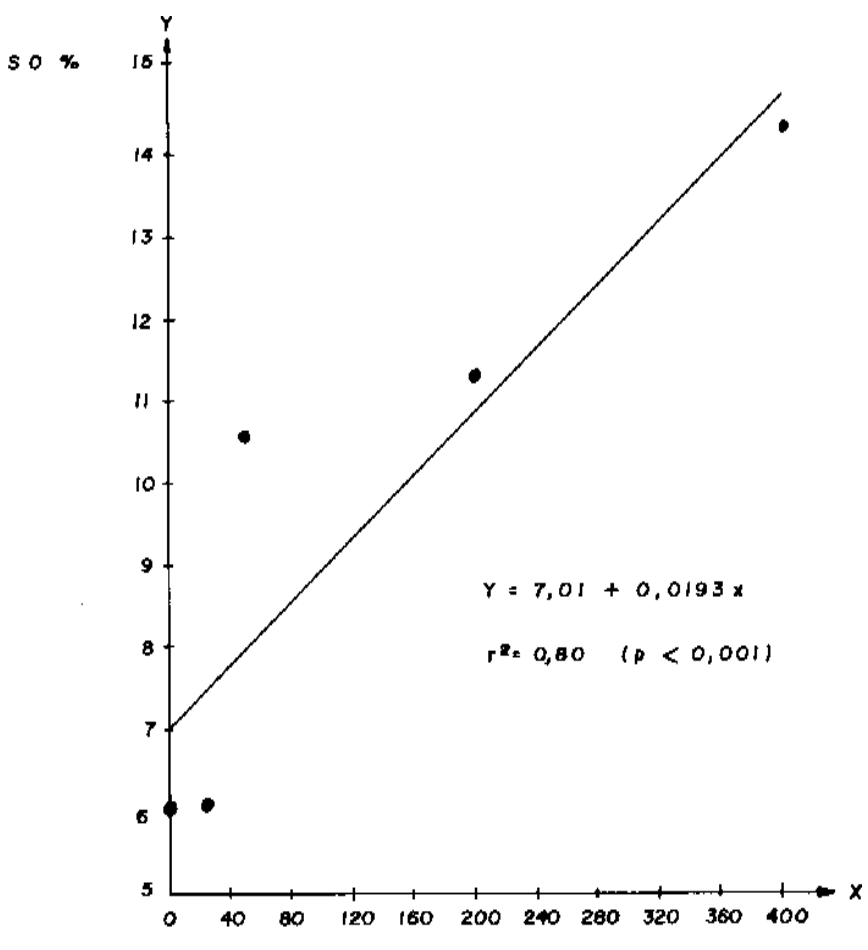

Fldor Dpm

Fig. 4. Representação gráfica da regressão linear, da superfície de osteóide (SO) no osso trabecular, nos animais suplementados com diferentes níveis de flúor.

animais tratados com 200 e 400 ppm em relação aos demais tratamentos e ao grupo controle.

No osso cortical da diáfise da tíbia observou-se diminuição do diâmetro dos canais de Havers próximos à superfície periosteal e aumento das lacunas de reabsorção localizadas próximas à superfície endosteal. Estas alterações foram evidentes nos animais tratados com 200 e 400 ppm e não foram observadas nos demais tratamentos.

No grupo B observou-se um aumento da espessura trabecular óssea, nos animais tratados com 200 e 400 ppm, quando comparados ao testemunha. Os demais grupos de tratamento não apresentaram alterações importantes da espessura trabecular quando comparados ao grupo controle. Alguns animais do grupo 400 ppm apresentaram formação de trabéculas transversas na esponjosa primária.

Nos animais tratados com 200 ppm observaram-se muitas trabéculas ósseas com lacunas de Howship cobertas por osteoclastos. Essas células eram as que predominavam nos animais desse tratamento. No tratamento 400 ppm, as células que predominavam eram os osteoblastos ativos. Quando comparados, os animais deste tratamento, com os demais tratamentos do mesmo grupo, era evidente, também, que o número de osteoblastos ativos era maior no tratamento de 400 ppm.

As alterações do osso cortical da tíbia foram similares às observadas nos animais do grupo A. 
Quadro 2. Concentração de flúor, em porcentagem, da tíbia, nos animais do grupo A e B (tratados durante 120 dias e 60 dias, respectivamente) suplementados com diferentes níveis de flúor

\begin{tabular}{cccccc}
\hline \multirow{2}{*}{ Níveis de flúor } & \multicolumn{2}{c}{ Grupo A } & & \multicolumn{2}{c}{ Grupo B } \\
\cline { 2 - 3 } \cline { 5 - 6 } ppm & $\begin{array}{c}\text { Osso } \\
\text { compacto }\end{array}$ & $\begin{array}{c}\text { Osso } \\
\text { trabecular }\end{array}$ & $\begin{array}{c}\text { Osso } \\
\text { compacto }\end{array}$ & $\begin{array}{c}\text { Osso } \\
\text { trabecular }\end{array}$ \\
\hline 0 & 0,106 & 0,045 & & 0,106 & 0,045 \\
25 & 0,487 & 0,470 & & 0,175 & 0,146 \\
50 & 0,651 & 0,402 & & 0,334 & nd $^{\mathrm{a}}$ \\
200 & 1,231 & 1,031 & & 0,867 & 0,647 \\
400 & 2,232 & 1,689 & & 1,657 & nd \\
\hline
\end{tabular}

a nd= valores não determinados

Determinação do flúor

A quantidade de flúor presente nas cinzas ósseas da tíbia são apresentados no Quadro 2.

\section{DISCUSSÃO E CONCLUSÕES}

Neste trabalho verificou-se através do estudo histomorfométrico, que os animais tratados com flúor, apresentaram um aumento significativo na espessura do osso cortical, sendo esse aumento maior nas doses de 200 e 400 ppm. Resultados similares foram observados por Lagier (1978) e Boivin et al. (1987) em biópsias de humanos com fluorose crônica.

O flúor não causou variações significativas na porosidade do osso cortical, em nenhum dos grupos de tratamento. No entanto, observando-se o Quadro 1, verifica-se uma tendência ao aumento da porosidade nos níveis de 25,50 e 200 ppm, no grupo B. O aumento da porosidade do osso cortical é uma alteração frequientemente encontrada em indivíduos expostos ao flúor, sendo que a maioria dos estudos têm sido realizada em pessoas com sintomatologia clínica de fluorose. (Bang et al. 1978, Baud et al. 1978, Boivin 1978, Boivin et al. 1987).

O fato de não se observarem alterações macroscópicas nem resultados significativos na porosidade do osso cortical, poderia estar relacionado com a espécie animal utilizada neste experimento, pois a sensibilidade ao flúor varia de acordo com a espécie. Os bovinos são considerados a espécie mais sensível à intoxicação por flúor (Suttie 1980, Shupe \& Olson 1983), e as aves a espécie mais resistente (Shupe \& Olson 1983). Para esses autores a sensibilidade à intoxicação por flúor, obedece uma escala decrescente: bovinos, caninos, equinos, ovinos, suínos e aves (Shupe \& Olson 1983).

Os resultados obtidos, neste trabalho, para ET demonstraram que a mesma foi significativamente maior nos animais tratados com flúor quando comparados ao grupo controle (Fig. 2). Esses resultados coincidem com os observados por Kragstrup et al. (1984). Outros autores não constataram diferença estatisticamente significativa da ET (Bang et al. 1978, Baud et al. 1978, Boivin 1978), embora, os valores obtidos em indivíduos expostos ao flúor, tenham sido maiores do que para os do grupo controle (Boivin 1978).

$\mathrm{O}$ aumento progressivo da ET, a medida que aumenta a dose de flúor, observado nos animais que ingeriram flúor durante 60 dias (grupo B), evidencia um efeito positivo do flúor sobre a aposição ou formação óssea, e que a mesma, estaria diretamente relacionada com a quantidade de flúor ingerida. No entanto, no grupo A, que ingeriu flúor durante 120 dias, observou-se um aumento progressivo da ET somente nas doses de 25, 50 e 200 ppm, porém, no nível de 400 ppm houve um decréscimo da ET (Fig. 2). Quando comparados os valores da ET, do grupo A com os do grupo B, observou-se que os valores foram inferiores nos animais que ingeriram flúor durante 120 dias (grupo A), demonstrando que a medida que se aumenta o tempo de exposição ao flúor verifica-se um efeito tóxico do flúor sobre os osteoblastos (Riet-Correa et al. 1983, Boivin et al. 1987). Observou-se, também, uma influência da dose (Fig. 2), onde ambos grupos apresentam uma regressão quadrática. No grupo A, ocorreu um decréscimo da ET na dose de 400 ppm e, quando comparados os animais desse grupo com os animais do grupo B, no mesmo tratamento, a diferença foi estatisticamente significativa $(\mathrm{p}<0,01)$.

Daijei (1984) e Krishnamachari (1986), em humanos, e Coutelier et al. (1978) em bovinos, encontraram hiperostose associada à ingestão de baixas doses de flúor e lesões de osteomalácia e osteoporose em consequência da ingestão de altas doses de flúor durante um longo período de tempo. A osteopetrose e hiperostose ocorreriam em intoxicações moderadas devido a diminuição da reabsorção, por lesão nos osteócitos, já a osteoporose seria consequência de intoxicações graves que causariam osteonecrose e lesões nos osteoblastos (Krook \& Maylin 1979). No entanto, outros autores evidenciaram osteoporose sem osteonecrose, provavelmente em consequência de que a lesão sobre os osteoblastos foi mais grave que a lesão sobre os osteócitos (Riet-Correa et al. 1983).

O VTO foi significativamente maior nos animais tratados com flúor, tanto para o grupo A como para o $\mathrm{B}$, quando comparados com os testemunhas, como observa-se na Figura 3. Os resultados deste experimento são similares aos observados em diversos estudos de fluorose humana, onde os autores obtiveram diferença significativa no VTO de indivíduos expostos ao flúor quando comparados os indivíduos normais que viviam em áreas livres da contaminação por flúor. (Bang et al. 1978, Baud et al. 1978, Boivin et al. 1987).

Na análise de regressão do VTO, do grupo B, observou-se uma resposta linear (Fig. 3), indicando que houve uma relação direta da dose de flúor ingerida com o VTO, ou seja, quanto maior a dose de flúor utilizada maior foi o valor do VTO encontrado. Isto pareceria indicar que o flúor provocou um estímulo na aposição óssea. No entanto, a regressão do VTO para o grupo $\mathrm{A}$, apresentou uma regressão quadrática, demonstrando que houve um estímulo favorável do flúor causando um aumento do VTO até a dose de 200 ppm, e que, os animais tratados com 400 ppm apresentaram um decréscimo do VTO quando comparados aos demais tratamentos. Estes dados evidenciam que, neste trabalho, considerandose as doses utilizadas e o período de tempo experimental, pareceria evidente que, nas aves, as primeiras alterações ósseas da fluorose correspondem a um aumento da espessura 
e do volume trabecular e que, $o$ aumento da dose e do tempo de exposição levaria a uma diminuição da quantidade de osso mineralizado.

A porcentagem de SO aumentou consideravelmente nos animais tratados com flúor quando comparados ao grupo testemunha (Fig. 4). $\mathrm{O}$ aumento foi gradativo e proporcional à dose de flúor, ou seja, quanto maior a dose de flúor administrada maior foi a SO observada. Chavassieux et al. (1987) em trabalho realizado com ovinos, Kragstrup et al. (1984) em experimento com suínos e Boivin et al. (1987) e Teotia et al. (1985) em estudos realizados em humanos, obtiveram resultados similares no estudo da superfície de osteóide.

$\mathrm{O}$ aumento crescente da SO parece indicar uma ação direta do flúor sobre os osteoblastos, estimulando-os a produzir o osteóide. Fato semelhante tem sido mencionado por Boivin et al. (1987) e Chavassieux et al. (1987) que observaram um aumento da SO associada a um aumento no número de osteoblastos ativos.

Quando analisamos os parâmetros estudados para o osso trabecular: ET, VTO e SO observamos que, no grupo B, houve um aumento de todos esses parâmetros, em todos os níveis de tratamento, indicando um efeito positivo do flúor sobre o tecido ósseo, e que isto seria devido a um estímulo sobre a aposição óssea, provavelmente por uma ação sobre os osteoblastos.

No grupo A constatou-se um aumento crescente da SO, em todos os níveis de tratamento, porém, quando observamos os valores obtidos para ET e para o VTO verificamos que houve um aumento desses parâmetros até a dose de 200 ppm e que, no tratamento de $400 \mathrm{ppm}$ ocorreu uma diminuição do VTO e da ET. Isso ocorre, provavelmente, devido ao estímulo que o flúor exerce na aposição óssea, evidenciado pelo aumento da SO e, em determinado momento, possivelmente em função da dose e do tempo de exposição, o flúor exerceria um estímulo direto ou indireto na reabsorção óssea levando a uma diminuição do VTO e da ET.

Segundo Kragstrup et al. (1984) as alterações ósseas induzidas pelo flúor, não são decorrentes da ação deste em apenas um tipo celular ósseo, mas, afeta todas as células envolvidas, direta ou indiretamente, no mecanismo de remodelação óssea. Lagier (1978) e Boivin et al. (1987) consideram que a fluorose está associada com um aumento das superfícies de remodelação; porém, ocorre um desequilíbrio em favor da formação óssea, com frequentes defeitos de mineralização, devidos provavelmente a um duplo efeito sobre os osteoblastos provocando um aumento no número de osteoblastos mas, também, ocasionando um efeito tóxico sobre essa célula (Boivin et al. 1987).

As alterações ósseas observadas neste trabalho poderiam, também, ser devidas a um efeito direto do flúor sobre os osteoblastos, estimulando-os a produzir matriz orgânica, já que se observou um aumento do VTO e da ET, e, principalmente, um aumento crescente da SO em todos os tratamentos. Porém, dependendo da dose e do tempo de exposição, o flúor teria um efeito tóxico sobre os osteoblastos e, em consequência, o osteóide formado não se mineralizaria adequadamente. Isto poderia explicar por que, apesar do aumen- to da superfície de osteóide, ocorreu uma diminuição do VTO e da ET na dose de $400 \mathrm{ppm}$ do grupo A.

Diversos autores observaram defeitos de mineralização da matriz orgânica, tanto em estudos experimentais em camundongos como em casos de fluorose industrial em humanos (Baud et al. 1978, Boivin et. al. 1978). Dois processos associados têm sido observados em ossos fluoróticos: o primeiro, consiste em uma aposição óssea deficientemente mineralizada, que resulta na formação de lacunas periosteocíticas de aspecto mosqueado nas microrradiografias; isso seria devido, provavelmente, a alguma perturbação que impediria a transformação normal dos osteoblastos em osteócitos e, evidentemente o flúor exerce um efeito direto ou indireto nesse processo. $\mathrm{O}$ segundo processo é uma reabsorção secundária que causaria o aumento das lacunas periosteocíticas. Certamente existem osteoblastos com diferentes capacidades de responder a um mesmo estímulo. Aqueles osteoblastos mais sensíveis ao flúor, poderiam transformar-se em osteócitos perturbados ou deficientes resultando na formação de lacunas mosqueadas ou fracamente mineralizadas. Os osteoblastos não sensíveis ao flúor transformariam-se em osteócitos normais com lacunas normais, onde o flúor poderia, mais tarde, acentuar a osteólise osteocítica provocando a formação de lacunas aumentadas (Boivin et al. 1978).

A quantidade de flúor presente nas cinzas ósseas, apresentou um incremento, em todos os níveis de tratamento, sendo diretamente proporcional ao aumento na suplementação com flúor. Estes dados, coincidem com os trabalhos onde houve determinação da quantidade de flúor nos ossos, tanto em intoxicações de animais (Shupe et al. 1963, Suttie 1967, Kragstrup et al. 1984, Chavassieux et al. 1987, Araya et al. 1990, Rubio et al. 1991, Zhou \& Zhai 1991, Jundong et al. 1992) como em humanos expostos ao flúor (Bang et al. 1978, Baud et al. 1978, Boivin et al. 1987). Através da determinação do conteúdo de flúor nos ossos ficou evidenciada a incorporação deste nos ossos dos frangos nesse experimento. O flúor, no organismo, apresenta grande afinidade por tecidos duros mineralizados, nos quais ele substitui a hidroxila do componente apatita, havendo a substituição do composto hidroxiapatita por fluorapatita (Eanes 1983).

Quando se compara o conteúdo de flúor presente nas cinzas ósseas do grupo A com o grupo B, observa-se que no grupo A, a quantidade de flúor é maior, e isto deve-se a um período mais prolongado (120 dias) de exposição ao flúor. Chavassieux et al. (1984) observaram resultados similares em experimento realizado com ovinos suplementados por dois diferentes períodos: 45 e 90 dias, sendo que os animais tratados durante 90 dias apresentaram as maiores concentrações de flúor nos ossos.

Através do estudo histológico observou-se um espessamento trabecular nos animais tratados com flúor, quando comparados ao testemunha, sendo esta alteração mais evidente nas doses de 200 e $400 \mathrm{ppm}$, tanto no grupo A como no grupo B. Estes resultados coincidem com os achados da histomorfometria, onde se observou aumento da ET 
em todos os níveis de tratamento, quando comparados ao grupo controle.

Sobre a superfície trabecular dos ossos dos animais tratados com 200 e 400 ppm, do grupo A, observou-se que havia, aparentemente, um maior número de osteoblastos ativos e osteoclastos, quando comparados aos frangos do grupo controle. Isso parece indicar que estaria ocorrendo um processo ativo de remodelação óssea, e que estaria relacionado diretamente com a dose de flúor, já que nas doses de 25 e 50 ppm não observaram-se diferenças com os testemunhas.

Nos animais do grupo B, na dose de 200 ppm, observouse muitas trabéculas ósseas com lacunas de Howship cobertas por osteoclastos, evidenciando um processo ativo de reabsorção óssea. Aumento da superfície de reabsorção com presença de osteoclastos, também tem sido observados em ossos de indivíduos expostos a fluorose endêmica (Teotia et al. 1985). Nos animais que ingeriram a dose de $400 \mathrm{ppm}$, as células que revestiam as superfícies trabeculares eram, principalmente, os osteoblastos ativos. Essas células eram observadas em número maior nos ossos dos frangos desse tratamento em relação aos demais do mesmo grupo. $\mathrm{O}$ aumento do número de osteoblastos é frequentemente associado à ingestão de flúor (Boivin et al. 1987, Chavassieux et al. 1987) o qual, provavelmente, atua sobre essas células estimulandoas a produzir o osteóide, como foi discutido anteriormente. A presença de grande número de osteoblastos que estariam produzindo matriz orgânica, é condizente com o aumento da superfície de osteóide verificado no estudo histomorfométrico. Fato semelhante é mencionado no estudo da fluorose em ovinos (Chavassieux et al. 1987) e em humanos (Boivin et al. 1987).

Em alguns casos de intoxicação por flúor tem sido observado osteonecrose (Krook \& Maylin 1979, Mores \& Bellaver 1984). Neste experimento essa alteração não foi verificada, o que coincide com os dados observados por Riet-Correa et al. (1983), em estudo realizado em bovinos. Em humanos, a determinação da população de osteócitos, através de estudo histomorfométrico, não apresentou alterações significativas nos indivíduos expostos ao flúor (Bang et al. 1978, Baud et al. 1978).

As alterações histológicas observadas no osso cortical, dos animais tratados com flúor, na dose de 200 e 400 ppm, de ambos os grupos, caracterizaram-se por diminuição dos canais de Havers, próximos à superfície periosteal, e um aumento das lacunas de reabsorção próxima à superfície endosteal, o que sugere uma ação do flúor sobre a remodelação óssea. Estaria havendo estímulo na aposição óssea, observado através da diminuição dos canais de Havers, e estímulo na reabsorção óssea, evidenciado pelo aumento das lacunas de reabsorção.

Essas alterações observadas na histologia do osso cortical, poderiam ser a explicação de não se ter observado variações significativas estatisticamente na porosidade do osso cortical no estudo histomorfométrico. Isso parece evidenciar que, durante o período experimental, o flúor ainda estava provocando um estímulo sobre a formação óssea, no osso cortical, motivo pelo qual a porosidade ainda não era evidente no estudo quantitativo do osso. No osso cortical, as alterações parecem ocorrer de forma mais lenta que no osso trabecular; e é possível que o flúor tenha pouco efeito na estrutura do osso cortical (Kuntz et al. 1986). Os baixos percentuais de porosidade observados neste experimento, podem, também, ser devidos a idade dos animais, às doses utilizadas e/ou a espécie animal, já que as aves são, aparentemente, menos sensíveis ao flúor que outras espécies (Shupe \& Olson 1983).

Pelos resultados obtidos neste experimento, podemos concluir que as alterações iniciais induzidas pelo flúor nas aves, consistem em aumento do tecido ósseo, e o aumento do tempo de exposição e/ou doses elevadas causam uma diminuição da quantidade de osso mineralizado, demonstrando o caráter tóxico do flúor.

\section{REFERÊNCIAS}

Ammerman C.B. 1980. Introductory remarks for the Symposium on fluoride toxicosis in cattle. J. Anim. Sci. 51: 744-745.

Araya O., Wittwer F, Villa A. \& Ducom C. 1990. Bovine fluorosis following volcanic activity in the Southern Andes. Vet. Rec. 126: 641-642.

Bang S., Baud C.A., Boivin G., Demeurisse C., Gössi M., Tochon-Danguy H.J. \& Very J.M. 1978. Morphometric and biophysical study of bone tissue in industrial fluorosis, p. 168-175. In: Courvoisier B., Donath A. \& Baud C.A. (ed.) Fluorine and Bone. Proc. 2nd Symp. CEMO. Huber, Bern.

Baron R., Vignery A., Neff L., Silverglate A. \& Santa Maria A. 1983. Processing of undecalcified bone specimes for bone histomorphometry, p.13-35. In: Recker R.R. (ed.). Bone Histomorphormetry: Techniques and Interpretation. Florida, USA.

Baud C.A., Lagier R., Boivin G. \& Boillat M.A. 1978. Value of the bone biopsy in the diagnosis of industrial fluorosis. Virchows Arch. Path. Anat. and Histol. 380: 283-297.

Boivin G. 1978. Morphometric analysis of fluorotic bone tissue, p. 42-46. In: Courvoisier B., Donath A., \& Baud C.A. (ed.) Fluorine and Bone. Proc. 2nd Symp. CEMO. Huber, Bern.

Boivin G. \& Baud C.A. 1978. Osteocyte lacunae of fluorotic bone tissue: microradiographic, ultrastructural and morphometric studies, p. 47-55. In: Courvoisier. B., Donath A. \& Baud C.A. (ed.) Fluorine and Bone. Proc. 2nd Symp. CEMO. Huber, Bern.

Boivin G., Chavassieux P., Chapuy M.C., Baud C.A. \& Meunier P.J. 1987. Skeletal fluorosis: Iliac bone histomorphometry and bone fluoride content. J. Bone and Mineral Res. Program \& Abstracts, 9 th Annu. Scient. Meet. Am. Soc. Bone and Mineral Res. 2, Suppl. I.

Chavassieux P., Pastoureau P., Boivin G., Charhon S., Chapuy M.C., Delmas P.D. \& Meunier P.J. 1987. Effects of sodium fluoride on bone remodeling in ewes . Journal of Bone and Mineral Res. Program \& Abstracts, 9 th Annu. Scient. Meet. Am. Soc. Bone and Mineral Res. 2, Suppl. I.

Chongwan Z., Guizhou H.D. \& Guizhou W.E. 1983. Light microscopy and scanning electron microscopy of bony tissue in foodborner endemic skeletal fluorosis. Fluoride 16(4): 209-213.

Coutelier L., Noel H. \& Maldague, B. 1978. Bone remodeling alterations induced by fluor poisoning in the bovine. Symposium CEMO, p. 189-193.

Daijei, H. 1984. Further observations on radiological changes of endemic foodborner skeletal fluorisis. Fluoride 17(1): 9-14.

Eanes E.D. 1983. Effects of fluoride on mineralization of teeth an bones, p. 195-197. In: Shupe J.L., Peterson H.B., Leone N.C. (ed.). Fluorides Effects on Vegetation, Animals and Humans. Utah, USA.

Jundong W., Chongwan Z., Youfa C., Jinxi L., Jieping H., Weifeng W. \& Jianping C. 1992. A study of damage to hard tissue of goats due to industrial fluoride pollution. Fluoride 25(3): 123-130.

Kragstrup J., Richards A. \& Fejerskov O. 1984. Experimental osteo-fluorosis in the domestic pig: A histomorphometric study of vertebral trabecular bone. J. Dental Res. 63(6): 885-889. 
Krishnamachari K.A.V.R. 1986. Skeletal fluorosis in humans: A review of recent progress in the understanding of the disease. Progr. Food and Nutr. Sci. 10: 279-314.

Krook L. \& Maylin, G.A. 1979. Industrial fluoride pollution. Chronic fluoride poisoning in Cornwall Island cattle. Cornell Vet. 69 (Suppl. 8): 1-70.

Kuntz D., Marie P., Naveau B., Maziere B., Tubiana M. \& Ryckewaert A. 1986. Extended treatment of primary osteoporosis by sodium fluorid combined with hydroxycholecalciferol. Fluoride 19(1): 38-39.

Lagier R. 1978. Effects of fluorine on bone morphology, p. 32-41. In: Courvoisier B., Donath A. \& Baud C.A. (ed.) Fluorine and Bone. Proc. 2nd Symp. CEMO. Huber, Bern.

Luna L.G. 1968. Manual of Histologic Staining Methods of the Armed Forces Institute of Patholog. 3rd ed. McGraw Hill, New York. 258 p.

McCann H.G. 1968. Determination of fluoride in mineralized tissue using the fluoride ion electrode. Arq. Oral Biol. 13: 475-477.

Mores N. \& Bellaver C. 1984. Alterações ósseas em suínos relacionadas com excesso de flúor na alimentação. Anais I Congr. Nac. Veterinários Especialistas em Suínos, Curitiba, Paraná, p.57.(Resumo)

Riet-Correa F., Oliveira J.A., Méndez M.C. \& Schild A.L. 1983. Poluição industrial como causa de intoxicação por flúor em bovinos no município de Rio Grande. Pesq. Vet. Bras. 3(4): 107-114.

Riet-Correa F., Méndez M.C., Schild A.L., Oliveira J.A. \& Zenebon O. 1986. Lesões dentárias em bovinos e ovinos devidos à poluição industrial causada pela combustão de carvão. Pesq. Vet. Bras. 6(1): 23-31.
Rubio J.R.P., Angeles A.P. \& Ibargüengolitia J.A.C. 1991. Intoxication por fluor en conejos. Un caso de campo. Tec. Pec. Mex. 28(2): 103-109.

Shupe J.L. 1967. Diagnosis of fluorosis in cattle, p. 15-30. In: IV Int. Meet. World Assoc. Buiatris, Publ. no 4. Zurich, Switzerland.

Shupe J.L., Miner M.L., Green Wood D.A., Harris E.L. \& Stoddard G.E. 1963. The effect of fluorine on dairy cattl. II. Clinical and pathology effects. Am. J. Vet. Res. 24:.964-984.

Shupe J.L. \& Olson A.E. 1983. Clinical and pathological aspects of fluoride toxicosis in animals, p. 319-338. In: Shupe J.L., Peterson H.B., Leone N.C. (ed). Fluorides Effects on Vegetation, Animals and Humans. Utah, USA.

Suttie J.W. 1967. Vertebral biopsies in the diagnosis of bovine fluoride toxicosis. Am. J. Vet. Res. 28: 709-712.

Suttie J.W. 1980. Nutritional aspects of fluoride toxicosis. J. Anim. Sci. 51(3): 759-766.

Teotia S.P.S., Teotia M. \& Singh D.P. 1985. Bone static and dynamic histomorphometry in endemic skeletal fluorosis. Fluoride Res., Studies Environm. Sci. 27: 347-355.

Zhou T. \& Zhai X.I. 1991. Pathological study on experimental chronic fluorosis in sheep. Acta Vet. Zootech. Sinica 22(1):61-68. (Vet. Bull. 61(11), Abstr. 7998)

Zonta E.P. \& Machado A.A. 1982. SANEST - Sistema de análise estatística para microcomputadores. Registrado na Secretaria Especial de Informática sob $\mathrm{n}^{\circ} 060066$ - Categoria A, Pelotas, RS. 